\title{
BUSCAS CÊNICAS E POSSIBILIDADES MICRO-HISTÓRICAS NO CONTEXTO CATALÃO/ESPANHOL
}

\section{Luiz Humberto Martins Arantes}

Professor doutor associado e pesquisador junto aos Programas de Pós-Graduação em Artes e Teoria Literária; e da Graduação em Teatro da Universidade Federal de Uberlandia, atualmente coordena na ABRACE O GT História das Artes do Espetáculo. 
Resumo: Este artigo faz uma breve passagem por questões teatrais e de identidade que foram possíveis de se perceber durante estágio na Catalunha espanhola. Caminhos de se fazer, escrever e pensar teatro que se traduzem em oportunidades para se refletir acerca dos pontos de partida para uma escrita da história do teatro ou história do espetáculo seja na Espanha seja no Brasil.

Palavras - chave: Teatro - identidade - história.

Abstract: This article is a brief passage through theater and identity issues that were possible to realize during stage in Spanish Catalonia, possibilities to do, write and think theater that translate into opportunities to reflect on the points of departure for a written history the history of theater or spectacle, whether in Spain is in Brazil.

Keywords: Theater - identity - history.

$\mathrm{Na}$ história da cultura brasileira e nas respectivas histórias da literatura, da dramaturgia e do teatro brasileiro a questão nacional, já faz algum tempo, tem sido problematizada e deixado de ser o centro ou o paradigma organizador das narrativas. Se não tanto, pelo menos se pode falar de uma crise nestes campos de estudo ao tentarem narrar suas histórias pelo viés da nacionalidade. Neste sentido, cada vez mais se procura falar das particularidades, inclusive regionais, principalmente, num país tão imenso e diverso como o Brasil. Diversos fatores explicam esta mudança, dentre eles, um mais geral, com certeza é a questão da globalização, seja econômica seja cultural, a partir dela flexibilizaram-se muitas fronteiras. Além das geográficas, houve também um entendimento sobre as 
localidades, as culturas e as respectivas práticas artísticas populares, de quaisquer tempos e lugares, as quais deveriam ser objeto de estudo e reflexão.

Em recente estágio em território espanhol foi possível ver e pesquisar o quão conflitante se tornou, naquele país, pensar e refletir sobre teatro e dramaturgia, principalmente a partir de chaves como o tema da nacionalidade. E também como este conflito tem, ainda hoje, motivado práticas teatrais e espaços culturais. Espanha e Catalunha ${ }^{1}$ podem, assim, ser um bom exemplo de como a história do teatro pode, sim, estar descolada de categorias nacionais, mas, ao mesmo tempo, também sublinham os cuidados que se deve ter para, a partir do regional, também não cheguemos a outro extremo, tão problemático quanto, qual seja: 0 nacionalismo ${ }^{2}$.

Pensando por este caminho, os estudos de micro-história podem ser uma interessante referência de recorte e também de análise para este teatro catalão e espanhol, pois o que se nota é a existência de vários estudos a partir daí. Fatores como uma delimitação geográfica e a existência de uma língua - o catalão colaborando para este recorte tão evidente. Mas, mais isso, nota-se a existência de uma prática teatral concernente à importância de se falar da existência de um teatro regional e não nacional, portanto, escrever sobre um teatro catalão e não espanhol.

As noções de micro-história e a experiência com o teatro catalão foram de suma importância para se perceber a necessidade de se construir uma história do teatro não apenas a partir da mudança de recorte espacial e cronológico, mas para além da hierarquizante relação centro/periferia, bom/mau teatro, profissional/amador e tantas outras mais. Isto requer adotar um entendimento da história como uma multiplicidade, como um ponto de vista assumido a partir de fatos, acontecimentos e

1 A histórica relação entre Espanha e Catalunha está muito bem desenvolvida no livro de Pierre Vilar sobre como se desenvolveu, ao longo do tempo e séculos, as tensões entre uma idéia de território e nacionalidade. Também explica como, atualmente, há uma elite política que se apropriou da bandeira de autonomia e independência para se perpetuar, pelo voto, em instância de poder na Catalunha. (VILAR, 2011, 23).

2 Consideram-se experiências extremas de nacionalismo aqui o que o século $\mathrm{XX}$ nomeou como Fascismo, na Itália, Nazismo, na Alemanha e por que não Franquismo, Salazarismo e Stalinismo na Espanha, Portugal e Rússia respectivamente. 
versões destes, narrada por um pesquisador que fala de um lugar específico, portanto, distinto dos demais por suas idiossincrasias e subjetividades.

Não seria possível, em poucas linhas, traçar aqui a histórica relação entre Catalunha e Espanha, seja de aproximação seja de tensionamento. Mas, para pensar a questão da nacionalidade e da regionalidade destes dois territórios no século XX, é importante reconhecer o papel que a Guerra Civil Espanhola (19361939) exerceu ao dividir o país em dois espaços e em duas propostas de país muito antagônicas.

A Catalunha foi a última trincheira de resistência ao avanço dos populares do General Franco, vindo a cair porque houve profunda divisão entre socialistas e comunistas no âmbito da resistência franquista em território catalão. Foi quando, então, os soldados de Franco avançaram e venceram. As conseqüências não poderiam ser piores, muitos se exilaram na França e no México e outros foram para campos de concentração no sul da França. Além, claro, daqueles que ficaram e sentiram as terríveis ameaças e torturas dos ocupantes.

A partir deste contexto vários desdobramentos aconteceram, pois, além dos relatos de violência, houve muita censura e impedimento às liberdades individuais e de expressão, o que atingiu fortemente o campo das artes e da cultura em geral. Talvez o mais impactante, na Catalunha, foi a proibição de se falar o catalão. Falar, escrever e divulgar toda uma cultura numa língua milenar.

Tal história - ou história regional - ou mesmo micro-história vem sendo construída a partir de experiências e práticas teatrais. A partir também de múltiplos espaços culturais, teatros oficiais e alternativos na cidade de Barcelona e, ainda, por uma rede de escolas e centros de formação em artes cênicas, públicos e privados, fomentadores de artistas e que também funcionam como instrumentos de incentivo e manutenção de público. Características que garantem a Barcelona a condição de cidade possuidora, mundialmente, da maior relação entre habitante $x$ frequentador de teatro ${ }^{3}$.

3 Segundo o dramaturgo Sergi Belbel, hoje diretor do Teatro Nacional da Catalunha (TNC), em recente palestra na Sala Beckett, Barcelona possui anualmente dois milhões de espectadores 
Esta proporção é garantida, primeiro, com a participação no investimento em cultura e em teatro. Isto pode ser notado na grande quantidade de espaços teatrais em Barcelona e compreendido a partir do plano diretor da cidade, sabe-se que ela se desenvolveu a partir da escassez de espaço urbano, portanto optou por um crescimento vertical. Assim, a maioria de seus prédios, na parte central, possui não mais do que seis andares, sendo a parte térrea restrita para serviços e comércios. Muitos desses andares térreos, por possuírem um pé direito alto, transformaram-se em teatros (exemplo: Teatro Almeria), colocando Barcelona no patamar de cidade com maior número de pequenos teatros no mundo.

Além dessa rede de teatros menores, nota-se ainda a criação e manutenção pelo setor público de muitos teatros maiores na cidade, garantindo um repertório dos mais variados. É o caso do Teatro Liceu, em plena Rambla Catalunha, onde oferece um catálogo de óperas, inclusive internacionais, durante todo o ano. Ali se apresenta com frequência uma 'prata da casa', isto é, os espetáculos operísticos e multimídia do reconhecido grupo La Fura dels Baus. Em virtude de sua história, o Liceu pode transmitir uma primeira impressão de ser um espaço aparentemente pomposo, mas possui também salas menores, diversificando os espetáculos em cartaz.

Outro espaço teatral bastante participativo da agitada vida teatral de Barcelona é o Teatro Nacional da Catalunha (TNC). Também possuidor de um edifício com várias salas - maiores e menores - tem se tornado ao longo dos anos defensor da cultura catalã. Para isso, nota-se uma intenção de ter em cartaz autores que escrevem em catalão e sobre temas que dizem respeito à cultura catalana. Atualmente é dirigido - artístico e administrativamente - por Sergi Belbel ${ }^{4}$, jovem

teatrais, para uma cidade que possui quase este número de habitantes, considerando a grande Barcelona.

4 Tarragona, 1965. Formado em letras pela Universidade Autônoma de Barcelona (UAB), foi aluno de José Sanches Sinisterra. No Brasil, conhecemos bastante seu texto "Carícias", publicado em Nova Dramaturgia Espanhola, 7Letras, 2001. 
autor com destacada atuação por suas peças contemporâneas, pensadas e escritas em catalão, mas traduzidas para o espanhol e em outras muitas línguas.

Criado a partir de 1976, o Teatro LLiure, outra importante casa teatral da cidade, consolidou-se como espaço de pesquisa e também de apresentação de repertório internacional e, se não fosse o Lliure, dificilmente conseguiria outras portas em Barcelona. Diferencia-se do grande circuito comercial existente na cidade pelo fato de ter sido aberto por uma cooperativa de artistas, em meados da década de 1970, e com um projeto claro de busca de um teatro de qualidade e formação de público também qualificado. Mas nunca deixando de lembrar que espaço e fazer teatral estão intimamente ligados ao lugar de onde se faz.

O Lliure quer ser um teatro que se projeta para o futuro a partir da ideia de refletir nossa imagem como povo e como cidadãos, rico, complexo, contraditório, nobre, excitante, atraente e, em última instância, nunca entediados. Um teatro onde o público constituiria uma montagem a cada dia, onde somos capazes de compartilhar os sentimentos do indivíduo e coletivo, e acima de tudo livre ${ }^{5}$.

(Fonte: http://www.teatrelliure.com/cat/quisom/tlliure.htm).

A existência destes espaços já consolidados não impede a existência de um circuito mais alternativo na cidade de Barcelona, uma das únicas cidades que se tem notícia da existência de uma associação de teatros alternativos. Espaços cênicos como o Llantiol sugerem a perseverança de uma boemia admiradora e praticante de um teatro pautado por uma dramaturgia calcada na palavra e na dimensão humana.

Com estrutura e projeto semelhante, o velho Tantarantana apresenta semanalmente espetáculos de bonecos e títeres, inclusive internacionais, atraindo o público infantil para uma das artes mais praticadas nesta milenar cidade. Mas que também não deixa de valorizar a história e cultura catalãs, como foi o exemplo do

5 Tradução livre do autor. 
espetáculo de bonecos sobre a vida do compositor catalão Pau Casals ${ }^{6}$. Neste espetáculo, em formato de bonecos, narra-se a trajetória do músico, portanto sua memória, num formato que seleciona trechos de uma vida para apreciação da criança.

Muito interessante verificar como uma biografia de vida, a trajetória de um único homem é adaptada para o universo infantil. Nota-se também uma seleção de momentos de vida, pois não há narrativa de cinqüenta minutos que consiga a intensidade de toda a vida de um músico. Pau Casals, nasceu, cresceu, aprendeu música em Barcelona, foi perseguido pelo Franquismo, viajou pelo mundo, morou em Paris, depois em Porto Rico. Além disso, criou um método para violoncelo, ainda hoje referência para os aprendizes do instrumento. É a cena teatral realizando aquilo que Carlo Ginzburg fez com seu moleiro em seu instigante projeto de microhistória.

Não se pode passar por Barcelona sem reconhecer a importância da Sala Beckett no cenário teatral da cidade. Hoje espaço de espetáculos e também de formação, sua história está ligada ao nome de José Sanches Sinisterra e seu antigo Grupo Fronterizo. Já com o nome de Sala Beckett tem investido em produções que valorizem a dramaturgia e a pesquisa de teatro contemporâneo, como exemplo o uso de tecnologias na cena teatral.

Através do Obrador Internacional, a Sala Beckett também realiza pesquisas e treinamento intensivo de novos autores, promovendo o teatro internacional e a difusão de novas formas e estéticas teatrais, com cursos básicos e especializados ao longo do ano, workshops, leituras encenadas, seminários, publicações e outras atividades. Nomes como Sergi Belbel, Lluïsa Cunillé, Josep Pere Peyró, Carles Batlle, Sarrias Mercè, David Plana e Pau Miró tiveram a Sala Beckett como espaço fundamental para a formação artística. A Sala também foi fundamental para aumentar o conhecimento na Catalunha do trabalho de escritores como Harold Pinter, Martin Crimp, Conor

6 A montagem sobre a vida do músico e maestro Pau Casals foi realizada pelo grupo ForaniTeatre de Barcelona, que esteve em cartaz no mês de novembro de 2011, no Teatro Tantarantana na mesma cidade. 
McPherson, Ronald Schimmelpfennig, Jon Fosse, Lars Norén, Juan Mayorga, Rafael Spregelburd e Javier Daulte, dentre outros. Faz quatro anos, a Sala Beckett organiza o "Obrador d'Estiu", um encontro de autores emergentes com propostas de trabalho, debates, criação de textos, leituras e cursos para profissionais durante uma semana de julho. A crescente internacionalização que está alcançando esta iniciativa deu um novo impulso e traçou novos objetivos para a Sala Beckett do futuro ${ }^{7}$.

(Fonte: http://www.salabeckett.cat/presentacion/trayectoria?set language $=\mathrm{ES}$ ).

A Sala Beckett possui uma sede com teatro próprio no bairro de Grácia em Barcelona, onde encena espetáculos experimentais, ministra cursos, mantém um site com divulgação de dramaturgia catalã e, ainda, mantém com periodicidade regular a publicação da revista Pausa, veículo de reflexão sobre dramaturgia e história do teatro catalão.

A questão da formação é de suma importância em Barcelona, pois são espaços como as escolas formais (públicas e privadas) e também escolas livres que garantem um teatro constantemente como objeto de estudo e reflexão. Tais espaços de ensino/aprendizagem devem, portanto, ser considerados na tessitura de uma história deste teatro regional.

O Instituto de Teatro e Dança de Barcelona foi instalado num lugar estratégico, na denominada 'cidade do teatro', ao lado do Teatro Lliure e do Mercat de les Flors, espaços de apresentação de teatro e dança. Portanto, a cidade soube aliar a questão da formação com a fruição. Assim, estudantes e espectadores convivem desde cedo com a movimentação destes espaços. No Instituto são formados atores, atuadores e performers em dança, para trabalharem na própria cidade e no mundo todo, pois Barcelona nas últimas décadas reforçou sua dimensão de metrópole cultural do mundo.

Além do Instituto muitas outras escolas particulares se somam para que Barcelona tenha um amplo leque de opções para a aprendizagem e treinamento 
teatral. Exemplo disso é o espaço Estúdio Berty Tobias, dirigido pelo pesquisador de mesmo nome, mas faz muitos anos investiga as possibilidades do método de preparação do ator francês Jacques Lecoq.

[...] Estudio Berty Tobias é hoje uma referência no cenário internacional e uma das melhores escolas do mundo que segue a linha iniciada por Jacques Lecoq de pedagogia teatral. A escola quer ser um lugar de encontro para compartilhar ideias, visões e experiências. Estudos realizados em vários idiomas coexistem e isso é algo que o caracteriza. No palco e nos bastidores escuta-se falar Espanhol, Catalão, Francês, Alemão, Inglês, Italiano, Português, Galego, Basco... No entanto, a língua comum utilizada é o Espanhol.[...].

(Fonte: http://www.teatrestudis.com/escuela.html)

Além deste, merece ser sublinhado também o trabalho de formação de artistas cênicos desenvolvido pelo grupo Moveo (centro de formação e criação em teatro físico e mímesis corporal dramática de Etiène Decroux). Seus fundadores vêm há muitos anos formando gente para teatro e dança a partir do método de Decroux, como também mantendo um grupo de montagens de espetáculos já bastante consolidado em Barcelona, pois advém de uma formação também sólida realizada junto ao Grupo Theatre de L’Ange Fou, de Londres.

A mímica corporal dramática de Etienne Decroux considera o corpo como o principal meio de expressão e o ator/atriz como ponto de partida para a criação, com o objectivo de 'tornar visível o invisível' (E. Decroux), permitindo-Ihe, assim, mostrar o pensamento por meio do movimento. A arte do movimento mais que a arte do silêncio. $A$ mímica corporal dramática é sobretudo a arte do ator. $O$ ator, independentemente de qualquer que seja sua ambição artística, deve estar, acima de tudo, no palco, e essa presença é medida através de seu corpo. Este é o seu meio de expressão. O corpo é o que o sustenta, é a primeira coisa que o espectador vai ver, o corpo é que leva a voz. É o esqueleto, de mãos dadas. Tomando o corpo como o centro de suas pesquisas, o ator/atriz de mímesis corporal dramática busca reconstruir a essência do drama, Integrar no corpo os princípios de uma ação ou de uma situação dramática desequilíbrio, instabilidade, causalidade, ritmo - obtendo, assim, o controle desses estados. $O$ ator converte-se em escultor e escultura, artesão de uma inscrição de pensamento no espaço e matéria de seu próprio trabalho. (Fonte: http://www.moveo.cat/sp/mimosp.html) 
Além destes espaços de formação, públicos e privados, espalhados por Barcelona, nota-se uma grande concentração de oficinas cênicas das mais variadas técnicas e linguagens teatrais por toda a cidade. Além disso, há uma grande concentração de festivais de teatro e de dança que movimentam o meio teatral e arregimentam uma quantidade cada vez maior de espectadores, elevando a cidade à categoria de pólo possuidor, no mundo, da maior densidade de público freqüentador de teatro, isto é, cerca de dois milhões de espectadores ao ano, como mencionado anteriormente.

Uma cidade que pesquisa e produz muito teatro gera também uma grande quantidade de vestígios deixados por estes espetáculos. Neste aspecto o teatro espanhol e a cidade de Barcelona são um bom exemplo no tocante à criação e manutenção de arquivos sobre memória das artes cênicas.

Os historiadores de boa formação sabem que não se faz história da cultura e do teatro sem documentação e fontes de pesquisa que permitam discutir os acontecimento e fatos do passado com credibilidade. Neste sentido, tanto Barcelona como Madrid são referências na constituição e preservação de acervos sobre história do teatro, sejam mantidos como museus sejam replicados como acervo virtual.

Em Barcelona, as Bibliotecas do Instituto de Teatro $^{8}$ e a Biblioteca da Catalunha garantem a riqueza de acervo bibliográfico em muitas línguas. Em termos de documentação acerca de uma pesquisa sobre teatro catalão e espanhol, o acervo disponibilizado pelo $\operatorname{MAE}^{9}$ (Centre de Documentació i Museu de les Arts Escèniques de l'Institut del Teatre) é dos mais interessantes para o pesquisador que busca fontes de pesquisa escritas, visuais e sonoras. O Instituto também oferece um museu de figurinos e de maquetes de cenário incrementando as opções para uma pesquisa de história do teatro na Catalunha.

8 http://www.institutdelteatre.org

9 http://www.cdmae.cat/ 
Neste sentido, o pesquisador irá encontrar no CDT (Centro de Documentação Teatral), situado em Madri, outra rica possibilidade de acervo para suas pesquisas. Mas aqui, de uma maneira mais ampla, pois o CDT disponibiliza acervo de muitas regiões da Espanha, principalmente sobre o teatro produzido no século $X X$, oferecendo muitos textos, fotos e vídeos.

Espanha, Catalunha e Barcelona são bons exemplos de que a existência de 'fazeres teatrais' carece de investimento e espaços culturais e, além disso, precisa de centros que organizem os vestígios e a memória deixada por artistas cênicos. Toda esta infraestrutura pronta em viabilizado a qualidade do trabalho do pesquisador de história do teatro. Neste sentido, torna viável e com menos obstáculos o trabalho do estudioso desejoso em aplicar os métodos e técnicas da história ou mesmo da micro-história.

As possibilidades de pesquisa de história do teatro se ampliaram consideravelmente nas últimas décadas. Principalmente no que diz respeito ao entendimento acerca da aceitação de fontes de pesquisa. Assim, a ideia de se incorporar novos objetos à pesquisa histórica atuou também nos estudos de história e memória do teatro, de maneira que as pesquisas, antes apoiavam-se nas fontes escritas, passaram a incorporar também as fotografias, os vídeos, os depoimentos orais e, enfim, todo e qualquer vestígio deixado por artistas cênicos e seus espetáculos.

Neste caminho, a micro-história pode, sim, ser uma opção de pesquisa, de prospecção de fontes e de narrativa de uma história do espetáculo por demais interessante. O mundo há muito deixou de ser indivisível, vivemos hoje um tempo norteado por múltiplas divisões, inúmeras relações entre o micro e a macro estrutura, em que os prótons, elétrons e nêutrons possuem e querem ser pontos de partida para muitas histórias.

A micro-história, assim, não é apenas redução de escala de análise, mas se sustenta também na idéia de que os vestígios podem ser sinais de amplitudes a serem desvendadas. Além de oportunizar aos esquecidos e excluídos a hora, a vez e a voz para se inserirem no tempo histórico. 
O teatro contemporâneo na Espanha parece dialogar com essa perspectiva, pois são tantas as possibilidades, são tantos os agentes artísticos que, se optarmos pelas narrativas da história tradicional, poucas experiências e artistas cênicos seriam incluídos. Esta ampliação do entendimento de fonte de pesquisa tem tornado crível outras, variadas e muito interessantes histórias do espetáculo, seja na Espanha seja no Brasil.

\section{Referências}

ARENDT, Hannah. Entre o passado e o futuro. São Paulo: Perspectiva, 1988.

CABAL, Fermin. Dramaturgia Española de Hoy. Madrid: Ediciones Autor/Tramart, 2009.

FOGUET, Francesc Et all. El Debat Teatral a Catalunya - antologia de textos de teoria i critica dramátiques (Del modernismo a La Guerra Civil). Barcelona: Institur Del Teatre, 2011.

GINZBURG, Carlo. O Queiro e os Vermes. São Paulo: Cia das Letras, 9ª ed., 1987. HALL, Stuart. Da Diáspora - identidades e mediações culturais. Belo Horizonte: Humanitas/Ed. UFMG, 2003, p.51-100.

LE GOFF, Jacques. Memória. In: História e Memória. Campinas: Ed. Da Unicamp, 1994.

PEIXOTO, Fernando. Um teatro fora do eixo. São Paulo, Editora Hucitec, 1993. $362 \mathrm{p}$.

VAINFAS, Ronaldo. Os protagonistas anônimos da história: micro-história. Rio de Janeiro: Ed. Campus, 2002. 163p.

VILAR, Pierre. Breve História de Cataluña. Barcelona: Ediciones UAB/El espejo y La lámpara, 2011. 